PREPARATION OF TEMPO-CELLULOSE

\title{
NANOFIBER/ZINC OXIDE AS ANTIMICROBIAL AND METHYLENE BLUE PHOTO-DEGRADING NANOCOMPOSITE
}

\author{
MOHAMED EL-SAKHAWY, AHMED SALAMA,* AHMED K. EL-ZIATY ${ }^{* *}$ \\ and HAZEM HASSAN*** \\ "Cellulose and Paper Department, National Research Centre, 33 El-Bohouth st., Dokki, \\ P.O. 12622, Giza, Egypt \\ ${ }^{* *}$ Chemistry Department, Faculty of Science, Ain Shams University Abbassia, Cairo, Egypt \\ ${ }^{* * *}$ Greater Cairo Sanitary Drainage Company (GCSDC), Central Labs, Cairo, Egypt \\ \Corresponding author: M. El-Sakhawy,elsakhawy@yahoo.com
}

Received November 3, 2020

\begin{abstract}
Photo-catalytic degradation of organic dyes in aquatic environments under visible light irradiation affords an efficient and economic technique for environmental remediation. TEMPO-oxidized cellulose nanofibers/zinc oxide nanocomposite (TEMPO-CNF/ZnO) was prepared through oxidation of cellulose pulp, followed by zinc oxide precipitation in the presence of oxidized fibers. TEMPO-CNF/ZnO was characterized by different techniques. The degradation rate of methylene blue $(\mathrm{MB})$ by TEMPO-CNF/ZnO was gradually increased with increasing $\mathrm{pH}$ and the degradation reached $86 \%$ within 340 minutes at $\mathrm{pH}$ 7. The kinetic study showed that the pseudo-first-order kinetic best fitted the photo-catalytic process. A mechanism was proposed for the degradation of MB using TEMPO-CNF/ZnO under visible light irradiation. TEMPO-CNF/ZnO showed high antibacterial activity against $S$. aureus and E. coli. Thus, the TEMPO-CNF/ZnO nanocomposite has been demonstrated to be an effective photo-catalytic material for degrading MB under visible light irradiation.
\end{abstract}

Keywords: TEMPO-oxidized cellulose, zinc oxide, composite, photo-degradation, dyes

\section{INTRODUCTION}

Photo-catalysis has emerged as a low-cost and facile strategy for the degradation of organic pollutants. ${ }^{1}$ Metal oxides, such as zinc oxide and silver oxide, are the most commonly used photocatalysts due to their photo-stability and interesting optical and mechanical properties. They harness the photo energy to produce active radicals that enhance the decomposition of organic pollutants. ${ }^{2}$ Semiconducting materials can produce active hydroxyl radicals when the energy of the photon is higher than the energy gap of the semiconductor. This energy transfers the electrons from the valence band to the conducting band, creating a hole that can generate hydroxyl radicals in an alkaline medium. These radicals are highly reactive and can enhance the oxidation of recalcitrant chemicals in wastewater, leading to complete degradation of organic pollutants into nontoxic low molecular weight molecules (such as $\mathrm{CO}_{2}$ and $\mathrm{H}_{2} \mathrm{O}$ ). The hydroxyl active radicals attack the organic materials via four different pathways: radical addition, hydrogen abstraction, electron transfer, and radical combination. ${ }^{3}$ However, the commonly used semiconductors, such as $\mathrm{TiO}, \mathrm{ZnS}$ and $\mathrm{CdS}$, with a wide band gap, higher than 3.0 $\mathrm{eV}$, can only absorb UV range light. Many studies were carried out for preparing highly efficient photo-catalysts, with narrower band gaps, which could well use the incident light to produce redox reactions. For example, ferromagnetic photocatalysts have been studied for preparing the required optical absorption with relatively narrow band gaps $(\sim 2 \mathrm{eV})$. The magnetic field of ferromagnetic photo-catalysts enables their separation from wastewater and they can be recycled for further use. Narrow-band-gab semiconductors are currently needed to generate more electron-hole pairs under visible light. Moreover, the morphology has a significant effect on the charge carrier efficiency of semiconductor 
photo-catalyst. ${ }^{4}$ Polysaccharides have been considered recently as host materials of metal oxides and inorganic nanoparticles. ${ }^{5,6}$ They can enhance the stability, control the special morphology, and assist the growth of nanoparticles. ${ }^{7,8}$ The exceptional features of metal nanoparticles, such as their electrical, magnetic, and optical properties, were preserved after immobilization on the polysaccharides. Metal nanoparticles/polysaccharides composite materials have been studied as a portable catalyst for water treatment, ${ }^{9}$ antimicrobial material ${ }^{10}$ and, recently, as a photo-catalyst. ${ }^{1,11}$

Cellulose nanofibers have several characteristics differing from those of conventional neat cellulose, such as specific surface area, special dimensions, morphology, crystallinity, and mechanical properties. Cellulose nanofibers based composites have a strong adsorption property and are a good candidate for wastewater treatment. ${ }^{12}$ The oxidation of cellulose pulp through 2,2,6,6tetramethyl piperidinyl-1-oxyl (TEMPO)-mediated oxidation is a promising process for preparing highly charged, carboxyl-functionalized cellulose nanofibers. ${ }^{13}$ TEMPO is highly stable nitroxyl radical, which is used in selective oxidation of primary alcohols to corresponding carboxylic acid and aldehydes in the presence of a primary oxidizing agent, such as sodium hypochlorite.

Nanostructured oxides of metals, such as magnesium, tin, titanium, zirconium and zinc, have interesting and unique morphological properties, including size depending properties, such as the scaling of the energy gap with a change in the electrical and optical properties. For example, a cellulose nanofibers/titanium dioxide composite was prepared and evaluated for photocatalytic activity under UV light. Composite films of $\mathrm{TiO}_{2}$ $\mathrm{CNF}$ were shown to be strongly photo-catalytically active in UV light, and subsequent modification with $\mathrm{Au}$ and $\mathrm{Ag}$ was displayed to improve their photo-catalytic efficiency in visible light. ${ }^{14}$ Among nanostructured metal oxides, $\mathrm{ZnO}$ is considered as one of the most important oxide materials due to its specific properties. It is used in several applications, such as photo-catalysis, antibacterial materials, dyes and sensitized solar cells. ${ }^{15,16}$ Several techniques have been applied to synthesize $\mathrm{ZnO}$ nanoparticles, such as the sol-gel method, vapor deposition, hydrothermal synthesis, thermal decomposition, precipitation, and spray pyrolysis. $^{17,18}$ For expanding its applications, numerous composites of $\mathrm{ZnO}$ have been broadly studied. Different studies investigated the synthesis of cellulose derivatives/ $\mathrm{ZnO}$ composites. Cellulose and its derivatives act as structural templates in the design and preparation of zinc oxide nanomaterials with many structural varieties. ${ }^{19}$ Cellulose derivatives/ZnO composite materials were applied to adsorb organic dyes and treat wastewater by destroying and breaking up organic pollutants.

The most successful demonstration for the treatment of wastewater was reported by using titanium oxide $\left(\mathrm{TiO}_{2}\right)$ and zinc oxide $(\mathrm{ZnO}){ }^{20}$ However, zinc oxide is a more efficient photocatalyst than $\mathrm{TiO}_{2}$, because it has high reaction rates owing to its high efficiency to generate hydroxyl ions. ${ }^{21}$ Moreover, $\mathrm{ZnO}$ enhances the possibility for visible-light photocatalytic activity. $^{22}$ For all these features, a cellulosic material $/ \mathrm{ZnO}$ composite is a promising candidate to remove organic pollutants, such as dyes, from wastewater. In the current study, 2,2,6,6tetramethylpiperidine-1-oxyl (TEMPO)-mediated oxidation was applied to produce TEMPO-CNF from cellulose pulp. Zinc oxide was prepared in the presence of oxidized cellulose fibers. The prepared TEMPO-CNF/ZnO was characterized and investigated as a photo-catalyst for organic pollutants from the wastewater, as well as an antimicrobial reagent to inhibit the growth of various bacteria and fungi.

\section{EXPERIMENTAL}

\section{Materials}

Bleached bagasse pulp was supplied by Qena Company of Paper Industry, Egypt. 2,2,6,6tetramethylpiperidine-1-oxyl (TEMPO) and zinc sulfate heptahydrate were purchased from Sigma Aldrich. All other chemicals were of analytical grades and used without further purification.

\section{Preparation of TEMPO-oxidized cellulose (TEMPO-CNF)}

TEMPO-oxidized bagasse pulp was prepared through the dispersion of $20 \mathrm{~g}$ of bleached bagasse pulp in distilled water with TEMPO $(0.8 \mathrm{~g})$ and sodium bromide $(8 \mathrm{~g}){ }^{23}$ Then, $300 \mathrm{~mL}$ of sodium hypochlorite solution (15\%) was added with continuous stirring and the $\mathrm{pH}$ was adjusted to 10 using $\mathrm{NaOH}$ solution. Then, the $\mathrm{pH}$ was adjusted to 7 and the oxidized fibers were centrifuged several times. Finally, TEMPO-CNF was dialyzed for 6 days. TEMPO-CNF was treated using a Masuko grinder as a mechanical defibrillation technique.

\section{Synthesis of TEMPO-CNF/ZnO}

The formed TEMPO-CNF was immersed in $50 \mathrm{~mL}$ of zinc sulfate heptahydrate solution $0.2 \mathrm{M}$. Then, $1 \mathrm{M}$ $\mathrm{NaOH}$ solution was dropped into the solution until the 
$\mathrm{pH}$ reached 9 under continuous stirring at room temperature. The TEMPO-CNF/zinc oxide was formed by drying the precipitate at $90{ }^{\circ} \mathrm{C}$ for 48 hours, then sieved to separate only zinc oxide nanoparticles.

\section{Characterization methods}

The attenuated total reflectance Fourier transform infrared (ATR-FTIR) spectra of materials were obtained using a Thermo Nicolet FT-IR Avatar 320, with a diamond crystal, and the spectra were recorded from 500 to $4000 \mathrm{~cm}^{-1}$. X-ray diffraction was performed with a scanning rate of $2 \theta=2.5 \%$ minute. Thermogravimetric analysis was accomplished with sensitivity measurements of $0.01 \mathrm{mg}$ and $25 \mu \mathrm{v}$, respectively. In each run, $10 \mathrm{mg}$ of sample was heated to $1273 \mathrm{~K}$, at a heating rate of $283 \mathrm{~K} / \mathrm{min}$ under $\mathrm{N}_{2}$ flow at a rate of $30 \mathrm{~mL} /$ minute. Scanning electron microscopy was conducted at $5-10 \mathrm{keV}$ at the National Research Center. Also, diffuse reflectance ultravioletvisible spectroscopy (UV-vis DRS) of the samples was carried out at room temperature using a UV-vis UNICO UV-2000 in the range of 200-1000 nm.

\section{Batch photo-catalytic degradation of MB}

The photo-degradation of MB was conducted in $100 \mathrm{~mL}$ of solution placed in a Pyrex reactor. The MB solution was introduced into the photo-reactor in addition to $0.5 \mathrm{~g}$ of TEMPO-CNF/ZnO nanocomposite. After achieving the adsorptiondesorption equilibrium, the sample was irradiated by visible light for a distinct time. During irradiation, agitation was maintained by an aerator to ensure a constant supply of oxygen and for stirring. $5 \mathrm{~mL}$ of sample was withdrawn from the bulk solution at predetermined time intervals and the degradation efficiency was determined by applying the following equation:

Degradation efficiency $(\%)=\left[\mathrm{C}_{\mathrm{o}}-\mathrm{C}_{\mathrm{t}} / \mathrm{C}_{\mathrm{o}}\right] \mathrm{X} 100$

where $\mathrm{C}_{\mathrm{o}}\left(\mathrm{mg} \mathrm{L}^{-1}\right)$ is the initial concentration dye and $\mathrm{C}_{\mathrm{t}}\left(\mathrm{mg} \mathrm{L}^{-1}\right)$ is its concentration at the time, $\mathrm{t}$. The concentrations of $\mathrm{MB}$ in the samples were determined and corresponding to the maximum absorption wavelength of MB. All the measurements were made in triplicate, with errors below 5\%, and average values were reported. The adsorption was studied in visible light with continuous stirring during the photocatalytic experiments. The decolorization was determined at the maximum wavelength of $630 \mathrm{~nm}$.

\section{Antimicrobial screening}

The antibacterial activity of TEMPO-CNF and TEMPO-CNF/ZnO was tested against two types of bacteria: (i) gram-negative: Escherichia coli ATCC 11775, (ii) gram-positive: Staphylococcus aureus ATCC 12600, as well as against Aspergillus flavus and Candida albicans ATCC 7102 as models of filamentous fungi using nutrient agar medium. The sterilized medium, autoclaved at $120^{\circ} \mathrm{C}$ for 30 minutes and incubated with one of the microorganisms, was put into a Petri dish to give a depth of $6.0 \mathrm{~mm}$. The examined films, with a diameter of $1 \mathrm{~cm}$, were placed on the seeded agar plate. After 24 hours of incubation at $37{ }^{\circ} \mathrm{C}$, the diameters of the inhibition zones were measured.

\section{RESULTS AND DISCUSSION Characterization of TEMPO-CNF/ZnO nanocomposite}

TEMPO-oxidation of cellulose pulp generates new carboxylic groups through selective oxidation of primary hydroxyl groups in the anhydroglucose units. The TEM image in Figure 1A displays TEMPO-CNF with the diameters in the range of 5-13 $\mathrm{nm}$. These results were obtained previously in our work. ${ }^{13}$ Moreover, the oxidized fibers have a uniform and homogeneous structure arising from the carboxylic groups, which assist the defibrillation of cellulose chains through the electrostatic repulsion force. Also, these groups could assist the cross-linking of the fibrils in different ways, such as the formation of intermolecular hydrogen bonding and supporting the formation of composites. In the current study, the carboxyl groups on TEMPO-CNF can be used to form a fully physically cross-linked nanocomposite with $\mathrm{ZnO}$.

Morphological analysis of TEMPO-CNF before and after zinc oxide mineralization is shown in Figure 1. SEM images of TEMPO-CNF exhibit random spatial organization and a nonhomogeneous distribution of fiber diameters. After zinc oxide precipitation, the surface morphology of the TEMPO-CNF/ZnO nanocomposite is relatively homogenous and the formed zinc oxide layer shows the presence of microplates with $\sim 0.5 \mu \mathrm{m}$ length. These plates appear to be distinct and uniform, likely due to the interaction between the TEMPO-CNF and the formed nanoparticles, which decreases the attractive forces among nanoparticles, reducing their aggregation tendency. Using bioactive cellulose to assist inorganic mineralization has been reported in the literature. ${ }^{24}$

TEMPO-CNF and TEMPO-CNF/ZnO nanocomposite were characterized by FTIR spectroscopy, as shown in Figure $2 \mathrm{~A}$ and $\mathrm{B}$. TEMPO-CNF exhibits a peak at $1160 \mathrm{~cm}^{-1}$ assigned to the $\mathrm{C}-\mathrm{O}-\mathrm{C}$ ether bonds, while the peak at $1630 \mathrm{~cm}^{-1}$ can be assigned to the carboxylate groups. The TEMPO-CNF/ZnO composite exhibits a characteristic band at 440 $\mathrm{cm}^{-1}$ due to the stretching mode of the zinc and 
oxygen bond, which confirms the presence of $\mathrm{ZnO}$ species in the final composite. Moreover, a peak at $1100 \mathrm{~cm}^{-1}$ may be attributed to $\mathrm{C}-\mathrm{O}-\mathrm{C}$ ether bonds. Also, a peak at $1623 \mathrm{~cm}^{-1}$, corresponding to the carboxylate groups, could be related to the adsorption of carboxylate onto $\mathrm{ZnO}$ structures. The broadband at $3300 \mathrm{~cm}^{-1}$ is assigned to $-\mathrm{OH}$ stretching. Moreover, the FTIR spectrum of the TEMPO-CNF gel exhibits a peak at $1160 \mathrm{~cm}^{-1}$, corresponding to the $\mathrm{C}-\mathrm{O}-\mathrm{C}$ ether bonds, while the peak at $1630 \mathrm{~cm}^{-1}$ corresponds to the carboxylate groups. ${ }^{25}$
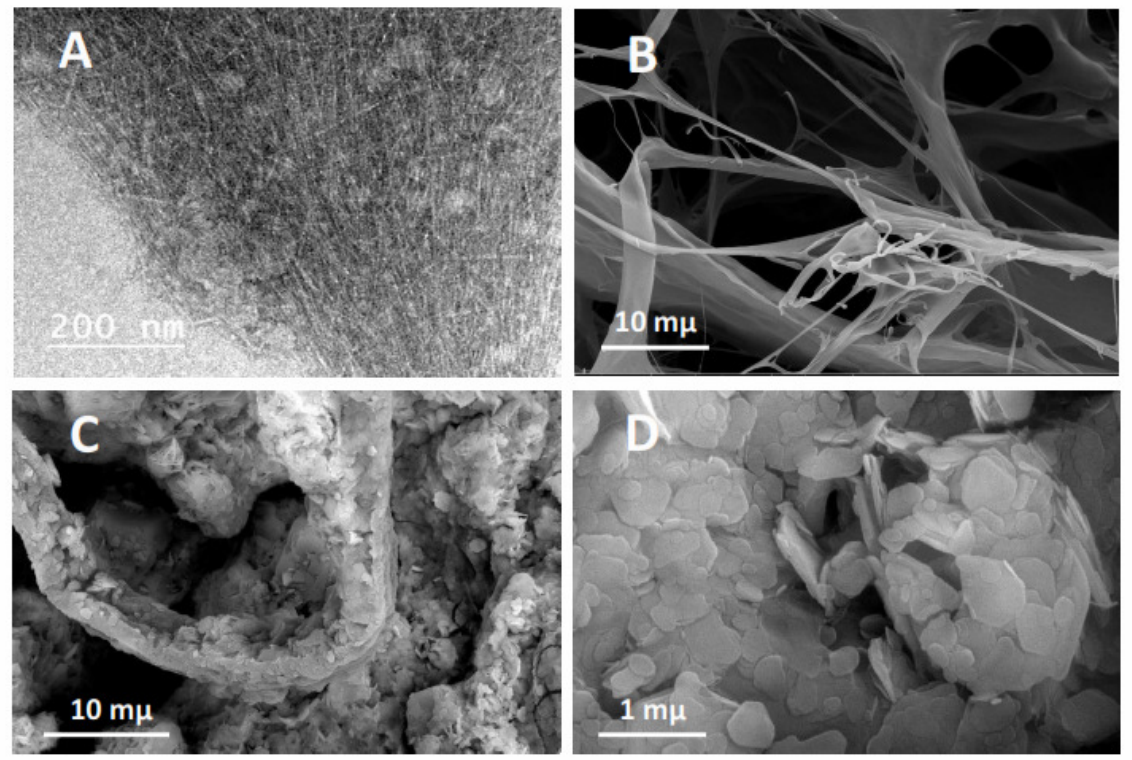

Figure 1: TEM image of TEMPO-CNF (A); SEM images of TEMPO-CNF (B) and TEMPO-CNF/ZnO nanocomposite at different magnifications $(\mathrm{C}$ and $\mathrm{D})$
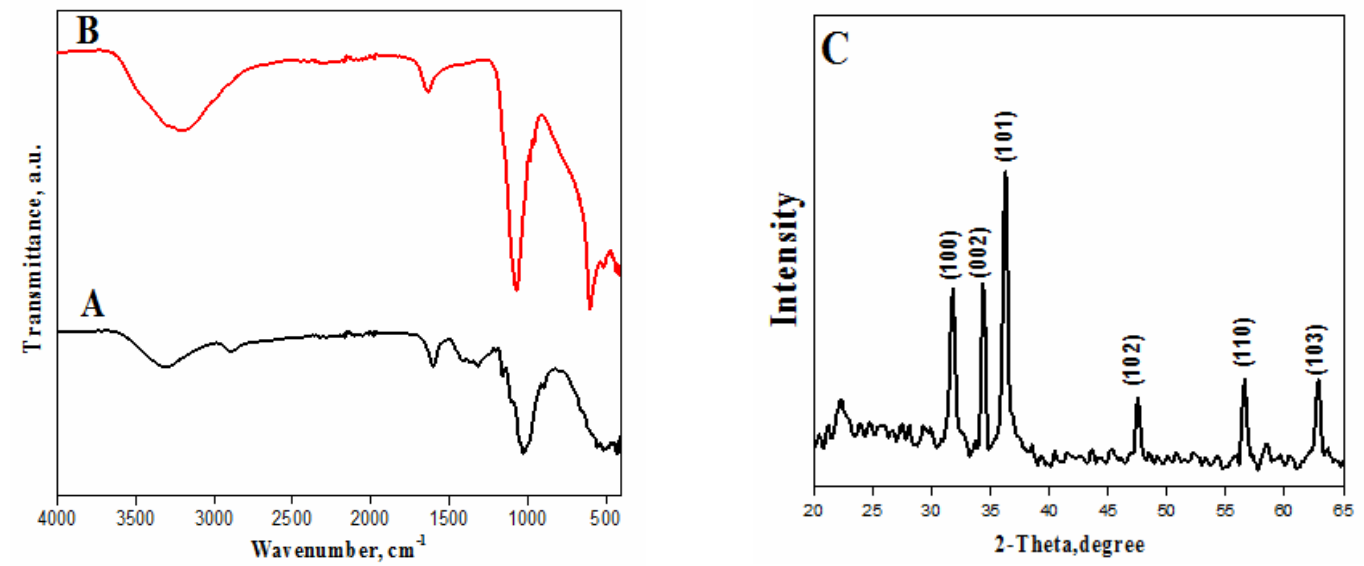

Figure 2: FT-IR spectra of TEMPO-CNF (A) and TEMPO-CNF/ZnO (B); XRD pattern of TEMPO-CNF/ZnO nanocomposite (C)

CNF was prepared and characterized by XRD in a previously published study. ${ }^{26}$ The XRD pattern of the TEMPO-CNF/ZnO nanocomposite is shown in Figure 2C. The TEMPO-CNF/ZnO nanocomposite exhibits peaks at $2 \theta$ values of $32^{\circ}$, $34.1^{\circ}, 35.2^{\circ}, 46.3^{\circ}, 58.6^{\circ}$ and $62.7^{\circ}$, assigned to the $\mathrm{ZnO}$ crystal planes of (100), (002), (101), (102), (110), and (103), respectively, which are indexed to the hexagonal $\mathrm{ZnO}$ wurtzite structure (JCPDS no. 36-1451). The results suggested the successful formation of crystalline $\mathrm{ZnO}$.

The thermogravimetric curves of TEMPO$\mathrm{CNF}$ and TEMPO-CNF/ZnO nanocomposite are shown in Figure 3. TEMPO-CNF and TEMPO$\mathrm{CNF} / \mathrm{ZnO}$ contain a layer of moisture, which is eliminated at $110^{\circ} \mathrm{C}$. The decomposition that can 
be seen in the thermogram curves of both TEMPO-CNF and TEMPO-CNF/ZnO between 250 and $300{ }^{\circ} \mathrm{C}$ was attributed to the decomposition of the cellulose fiber and the decomposition from $500{ }^{\circ} \mathrm{C}$ was attributed to the region of D-glucopyranose monomer and the thermal degradation of the organic part, ${ }^{27}$ it reached $76 \%$ of the mass loss, leaving $24 \%$ residue for TEMPO-CNF. ${ }^{28}$

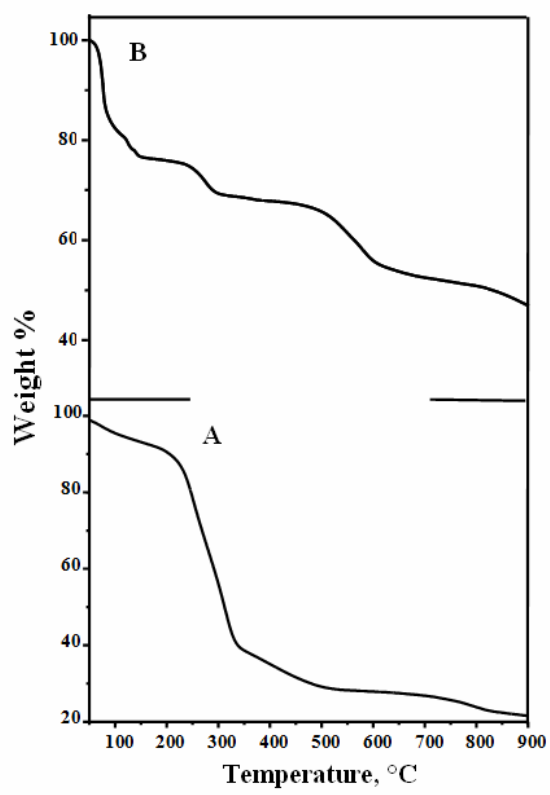

Figure 3: TGA curves of TEMPO-CNF (A) and TEMPO-CNF/ZnO (B)

However, the TEMPO-CNF/ZnO composite exhibits higher thermal stability, compared with pure TEMPO-CNF, along the whole studied temperature range, and shows a moderate steady degradation rate, without a sharp degradation peak between $200-400{ }^{\circ} \mathrm{C}$, in contrast to pure TEMPO-CNF. This could be attributed to the presence of $\mathrm{ZnO}$ nanostructures that can disperse within the cellulose fibers and shield them. The highly thermo-stable inorganic nanomaterials can improve the thermal degradation temperature of cellulose. It is known that $\mathrm{ZnO}$ has thermal stability over $900{ }^{\circ} \mathrm{C}$. ${ }^{29}$ The estimated mass loss of TEMPO-CNF/ZnO composite was $54 \%$, with a residual mass of $46 \%$, due to the presence of the thermally stable $\mathrm{ZnO}$ particles.

\section{Photo-catalytic degradation of MB using TEMPO-CNF/ZnO nanocomposite}

The photo-catalytic activity of the TEMPO$\mathrm{CNF} / \mathrm{ZnO}$ nanocomposite under simulated sunlight was examined using $\mathrm{MB}$ as a model for organic dye. Adsorption was accomplished via the charge and roughness of the nanocomposite surface. The equilibrium adsorption of $\mathrm{MB}$ by TEMPO-CNF/ZnO nanocomposite was reached after 90 minutes. Then, MB degradation started by visible light irradiation. The effect of adsorption and photo-degradation by the TEMPO$\mathrm{CNF} / \mathrm{ZnO}$ nanocomposite on $\mathrm{MB}$ concentration is shown in Figure 4A. MB shows a major absorption band at $655 \mathrm{~nm}$. The addition of TEMPO-CNF/ZnO nanocomposite to the MB solution under visible light illumination leads to an apparent reduction in absorption with a slight wavelength shift. The intensity at $655 \mathrm{~nm}$ decreases progressively in the course of the photo-degradation of $\mathrm{MB}$ via the aromatic ring opening.

The UV-visible light plays a vital role in nanosized semiconductors that could be controlled by calculating the band gap energy. The optical band gap was confirmed by using the Tauc relation. The Kubelka-Munk function is applied to convert the diffuse reflectance into an equivalent absorption coefficient and is generally used to analyze the powder sample by the extrapolation of the linear portion of the graph between $[\alpha h v]^{2}$ versus photon energy (hv), as shown in Figure 4B. The optical band gap energy value of the TEMPO-CNF/ZnO nanocomposite is $2.94 \mathrm{eV}$, which is in the blue region, compared to the bulk 
$\mathrm{ZnO}(3.3 \mathrm{eV})$. This could be referred to the additional sub-band-gap energy levels induced by the abundant surface and interface defects in the accumulated particles. ${ }^{30}$ This variation of band gap is an important aspect of the photo-catalytic activity of the TEMPO-CNF/ZnO nanocomposite.

The $\mathrm{pH}$ of the medium is an important parameter in the heterogeneous photo-catalysis process. The role of $\mathrm{pH}$ on the rate of photocatalytic degradation was studied in the $\mathrm{pH}$ range $2-7$. The degradation rate gradually increased as the $\mathrm{pH}$ increased, due to the presence of excess $\mathrm{OH}^{-}$anions that enhance the photo-generation of hydroxyl radicals and increase the rate of degradation, as shown in Figure 5A.

The time effect on the photo-catalytic performance of TEMPO-CNF/ZnO under visible light irradiation toward the photo-degradation of $\mathrm{MB}$ is shown in Figure 5B. The degradation is denoted as a relation between $(\mathrm{C} / \mathrm{Co})$ and irradiation time, where $\mathrm{Co}$ and $\mathrm{C}$ are the concentrations of $\mathrm{MB}$ at the initial time and at time t, respectively. From the results, it is clear that the degradation of $\mathrm{MB}$ reached $86 \%$ within 340 minutes when utilizing TEMPO-CNF/ZnO.

The rate constant values, $\mathrm{k}$, of both pseudofirst-order and pseudo-second-order kinetic models were used to fit the experimental data. The linearized forms of the pseudo-first-order and pseudo-second-order are given in Equations (1) and (2):

$$
\begin{aligned}
& (-) \ln \frac{C t}{C 0}=\mathrm{K}_{\mathrm{obs}} \mathrm{t} \\
& \frac{1}{C t}-\frac{1}{C 0}=\mathrm{K}_{\mathrm{obs}} \mathrm{t}
\end{aligned}
$$

where $\mathrm{k}_{\mathrm{obs}}$ : rate constant and at time $\mathrm{t}(\mathrm{min}), \mathrm{C}_{\mathrm{o}}$ : concentration at time 0 , and $\mathrm{C}_{\mathrm{t}}$ : concentration at a certain time.

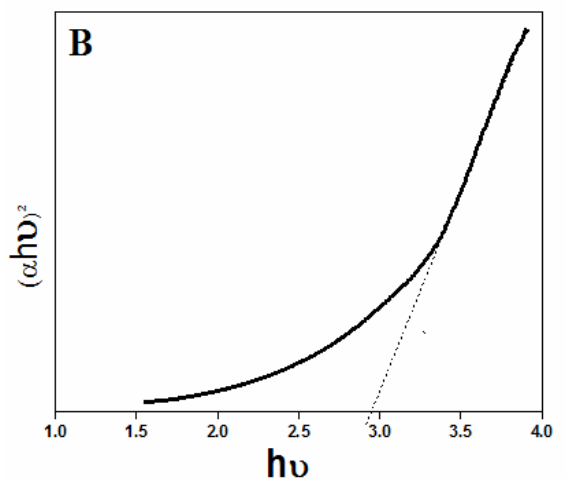

Figure 4: Adsorption and degradation contribute to lower MB concentrations (A); plots of $(\alpha \mathrm{h} v)^{2}$ versus hv of TEMPO-CNF/ZnO nanocomposites (B)
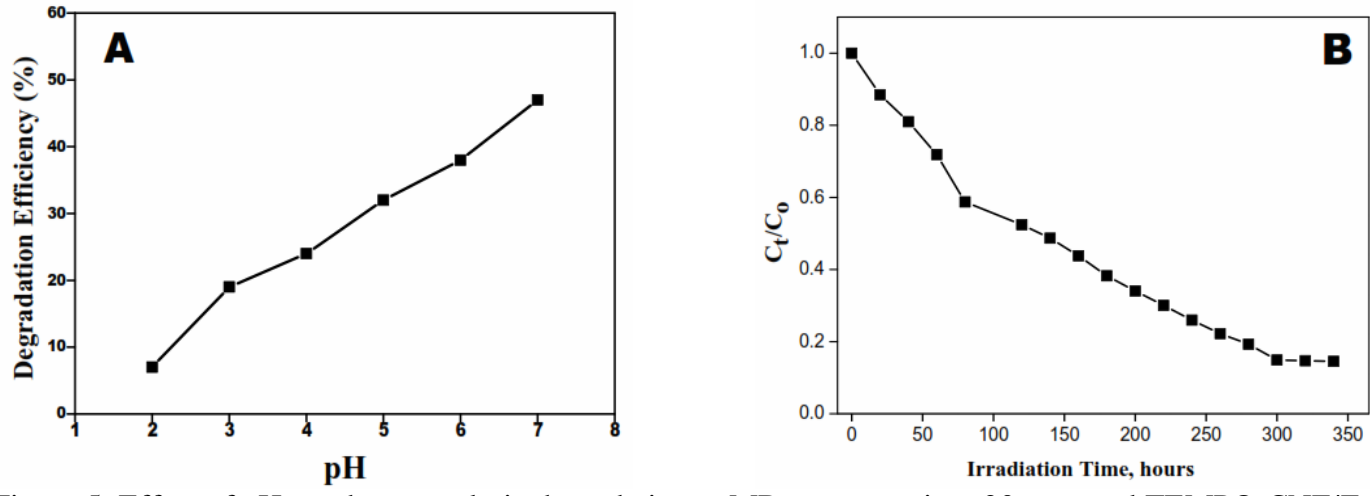

Figure 5: Effect of $\mathrm{pH}$ on photo-catalytic degradation at $\mathrm{MB}$ concentration: $20 \mathrm{ppm}$ and TEMPO-CNF/ZnO dose: $0.5 \mathrm{~g}$ (A); Effect of time on photo-catalytic degradation of TEMPO-CNF/ZnO at MB concentration: 20 $\mathrm{mg} / \mathrm{L}$; TEMPO-CNF/ZnO: $0.5 \mathrm{~g} / 50 \mathrm{~mL}$ and $\mathrm{pH}: 7.0$ (B) 


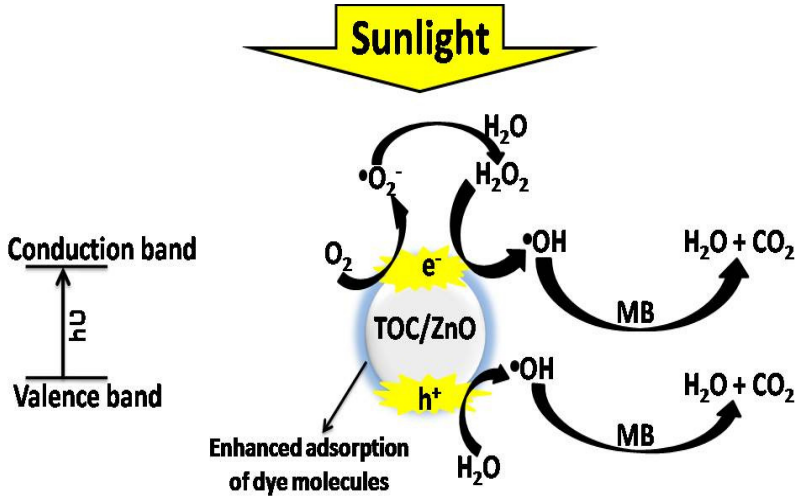

Figure 6: Mechanism of photo-catalytic degradation of MB by TEMPO-CNF/ZnO (TOC/ZnO)

The kinetic linear plots of (-) $\ln \frac{c t}{c o}$ versus $t$ and $\frac{1}{c_{0}}-\frac{1}{c 0}$ versus $\mathrm{t}$ are drawn for the pseudo-firstorder and pseudo-second-order models, respectively. The correlation coefficient obtained from the pseudo-first-order model $\left(\mathrm{R}^{2}=0.98\right)$ is higher than that from the other investigated model $\left(\mathrm{R}^{2}=0.88\right)$.

The mechanism of photo-catalytic activity of TEMPO-CNF/ZnO can be explained in terms of reactive oxygen species. TEMPO-CNF/ZnO is a semiconductor and it can generate electron-hole pairs after absorbing a photon. Low recombination between the excited electrons and holes is the significant characteristic of the TEMPO-CNF/ZnO to achieve good photocatalytic activity. Briefly, when visible light is irradiated on TEMPO-CNF/ZnO, electrons from its valence band get excited to the conduction band, leaving holes behind. These photogenerated electrons are captured by dissolved $\mathrm{O}_{2}$ in solutions to produce $\mathrm{O}_{2} \bullet^{-}$radicals. The thus obtained $\mathrm{O}_{2} \bullet^{-}$radicals can react with $\mathrm{H}^{+}$to produce $\mathrm{H}_{2} \mathrm{O}_{2}$, leading to the formation of $\mathrm{OH}^{*}$ radicals. Also, the photo-generated holes can react with $\mathrm{H}_{2} \mathrm{O}$ and $\mathrm{OH}^{-}$to produce $\mathrm{OH} \bullet$ radicals. Thus, the generated reactive oxygen species $(\mathrm{OH}$ radicals) are responsible for the photo-degradation of the organic dye solution. The possible photochemical reactions taking place can be summarized in Figure 6.

\section{Antimicrobial activity}

Liu and Yang suggested that photo-catalytic oxidation enhanced the disinfection capability toward gram-positive and gram-negative bacteria in wastewater. ${ }^{31}$

Isolated colonies of each organism were tested in terms of their susceptibility by the disc diffusion method.
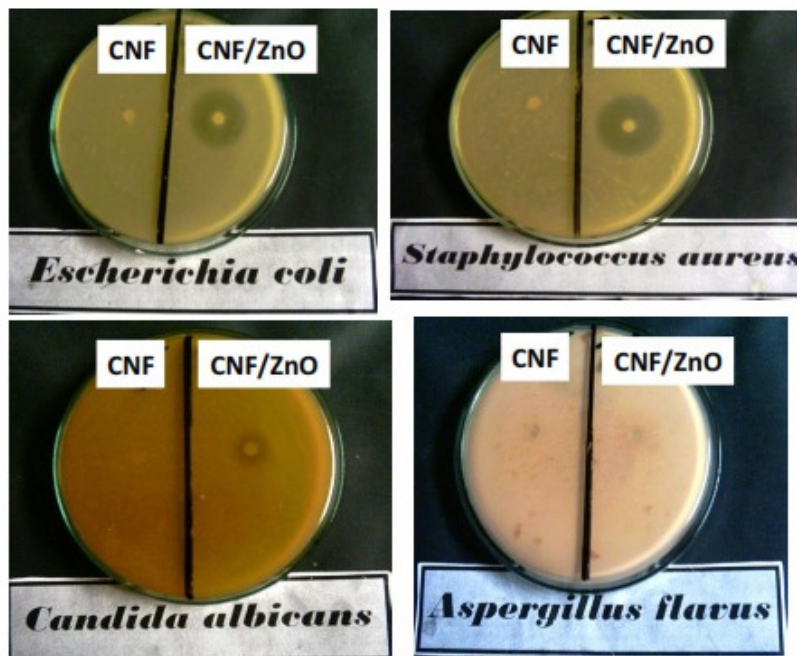

Figure 7: Antimicrobial activity of TEMPO-CNF and TEMPO-CNF/ZnO nanocomposite 
TEMPO-CNF exhibited low antibacterial activity ( $9 \mathrm{~mm}$ ) against both $S$. aureus and E. coli. Moreover, there is no activity recorded against the fungi species. However, the TEMPO-CNF/ZnO nanocomposite has high antibacterial activity against both gram-positive and gram-negative pathogenic bacteria $S$. aureus and E. coli (Fig. 7 and Table 1). The inhibition zones for the TEMPO-CNF/ZnO nanocomposite against $S$. aureus and $E$. coli were of 28 and $23 \mathrm{~mm}$, respectively. However, TEMPO-CNF/ZnO did not show antifungal activity toward Aspergillus flavus, while it showed moderate activity against Candida albicans. The inhibition zone against $C$. albicans was $14 \mathrm{~mm}$. The antimicrobial activity of the $\mathrm{ZnO}$ nanocomposite is due to the reactive oxygen species produced by zinc oxide. Thus, the zinc ions released will attack the negatively charged bacterial cell wall and cause cell wall leakage. The higher reactivity of the nanocomposite toward $E$. coli, compared to $S$. aureus, may be attributed to the presence of a thick layer of peptidoglycans in the cell wall of $S$. aureus, compared to E. coli. The gram-negative bacteria have a structure of cell wall relatively more complex than that of gram-positive cells. ${ }^{32}$ So, a longer oxidation time of the photo-catalyst would be required for inactivation of gramnegative bacteria by wall destruction during photo-catalytic inactivation. To conclude, the generated reactive oxygen species $(\mathrm{OH}$ radicals) are responsible for killing the bacteria

Table 1

Antimicrobial activity of the synthesized TEMPO-CNF and TEMPO-CNF/ZnO nanocomposites

\begin{tabular}{lcccc}
\hline Sample & \multicolumn{3}{c}{ Inhibition zone diameter (mm/mg sample) } \\
\hline & $\begin{array}{c}\text { Escherichia coli } \\
\left(\mathrm{G}^{-}\right)\end{array}$ & $\begin{array}{c}\text { Staphylococcus } \\
\text { aureus }\left(\mathrm{G}^{+}\right)\end{array}$ & $\begin{array}{c}\text { Aspergillus flavus } \\
\text { (fungus) }\end{array}$ & $\begin{array}{c}\text { Candida albicans } \\
\text { (fungus) }\end{array}$ \\
\hline Ampicillin & 25 & 21 & -- & -- \\
antibacterial agent & -- & -- & 17 & 21 \\
\hline \multirow{5}{*}{$\begin{array}{l}\text { Amphotericin B } \\
\text { antifungal agent }\end{array}$} & -0.0 & 0.0 & 0.0 & 0.0 \\
\hline Control: DMSO & 9 & 9 & 0.0 & 0.0 \\
TEMPO-CNF & 23 & 28 & 0.0 & 14 \\
TEMPO-CNF/ZnO & & & & \\
\hline
\end{tabular}

Table 2

Comparison of photo-catalytic degradation of MB by various photo-catalysts

\begin{tabular}{|c|c|c|c|}
\hline Photo-catalyst & $\begin{array}{c}\text { Percentage of } \\
\text { degradation }\end{array}$ & $\begin{array}{l}\text { Source } \\
\text { of light }\end{array}$ & $\begin{array}{c}\text { Initial conc. } \\
(\mathrm{mg} / \mathrm{L})\end{array}$ \\
\hline $\mathrm{ZnO}$ prepared by precept $^{33}$ & $81 \%$ & $\mathrm{UV}$ at $180 \mathrm{~min}$. & 20 \\
\hline $\mathrm{ZnO}$ prepared by sol-gel ${ }^{33}$ & $92.5 \%$ & $\mathrm{UV}$ at $180 \mathrm{~min}$. & 20 \\
\hline Cellulosic fibers coated with $\mathrm{ZnO}^{34}$ & $70 \%$ & $\mathrm{UV}$ at $480 \mathrm{~min}$. & 3 \\
\hline Cellulose/ZnO ${ }^{35}$ & $69.5 \%$ & Vis. at $60 \mathrm{~min}$. & 5 \\
\hline Cellulose/ZnO ${ }^{35}$ & $58.7 \%$ & Vis. at $90 \mathrm{~min}$. & 10 \\
\hline TEMPO-CNF/ZnO (current study) & $86 \%$ & Vis. at $340 \mathrm{~min}$. & 20 \\
\hline
\end{tabular}

Table 2 presents a comparative evaluation of available photo-catalysts for methylene blue dye. It can be observed that TEMPO-CNF/ZnO has better performance than other reported photocatalysts. TEMPO-CNF/ZnO is a promising candidate photo-catalyst that can save energy and degrade dyes.

\section{CONCLUSION}

A novel sustainable TEMPO-CNF/ZnO nanocomposite was synthesized by oxidation of cellulose pulp, followed by zinc oxide precipitation. The TEMPO-CNF/ZnO nanocomposite exhibited excellent photo-catalytic activity in the degradation of $\mathrm{MB}$ under visible light irradiation and the degradation of $\mathrm{MB}$ reached $86 \%$ in 340 minutes. The developed material showed antibacterial activity against $S$. aureus and E. coli. Thus, the prepared TEMPO$\mathrm{CNF} / \mathrm{ZnO}$ nanocomposite has been demonstrated as an effective antimicrobial and photo-catalytic material for degrading $\mathrm{MB}$ under visible light irradiation. 
ACKNOWLEDGEMENT: The authors would like to express their gratitude to the National Research Centre, Egypt, for the financial support of the current work.

\section{REFERENCES}

1 G. Zhang, L. Chen, X. Fu and H. Wang, Ind. Eng. Chem. Res., 57, 4277 (2018), https://doi.org/10.1021/acs.iecr.8b00006

2 R. Pandimurugan and S. Thambidurai, $A d v$. Powder Technol., 27, $1062 \quad$ (2016), https://doi.org/10.1016/j.apt.2016.03.014

3 C. Ren, B. Yang, M. Wu, J. Xu, Z. Fu et al., J. Hazard. Mater., 182, 123 (2010), https://doi.org/10.1016/j.jhazmat.2010.05.141

4 L. Gan, A. Geng, L. Xu, M. Chen, L. Wang et al., J. Clean. Prod., 196, 594 (2018), https://doi.org/10.1016/j.jclepro.2018.06.086

5 A. Salama and P. Hesemann, Int. J. Biol. Macromol., $\quad \mathbf{1 1 1}, 762 \quad$ (2018), https://doi.org/10.1016/j.ijbiomac.2018.01.049

6 M. El-Sakhawy, A. Salama, A. K. El-ziaty and H. Hassan, Cellulose Chem. Technol., 54, 601 (2020), https://doi.org/10.35812/CelluloseChemTechnol.2020. 54.60

7 A. Salama and P. Hesemann, Int. J. Biol. Macromol., $\quad 147, \quad 276 \quad$ (2020), https://doi.org/10.1016/j.ijbiomac.2020.01.046

8 A. Salama, Int. J. Biol. Macromol., 127, 606 (2019), https://doi.org/10.1016/j.ijbiomac.2019.01.130

9 J. Zeng, S. Liu, J. Cai and L. Zhang, J. Phys. Chem. C, 114, $7806 \quad$ (2010), https://doi.org/10.1021/jp1005617

10 A. Salama, Environ. Nanotechnol. Monit. Manag., 8, $228 \quad$ (2017), https://doi.org/10.1016/j.enmm.2017.08.003

11 Q. Li, D. Zhou, P. Zhang, P. Man, Z. Tian et al., Colloid. Surfaces A Physicochem. Eng. Asp., 501, 132 (2016), https://doi.org/10.1016/j.colsurfa.2016.04.054

12 A. Salama, S. Etri, S. A. A. Mohamed and M. ElSakhawy, Carbohyd. Polym., 189, 138 (2018), https://doi.org/10.1016/j.carbpol.2018.02.016

13 A. Salama, R. E. Abou-Zeid, I. Cruz-Maya and V. Guarino, Carbohyd. Polym., 229, 115472 (2020), https://doi.org/10.1016/j.carbpol.2019.115472

14 A. Snyder, Z. Bo, R. Moon, J. C. Rochet and L. Stanciu, J. Colloid. Interface Sci., 399, 92 (2013), https://doi.org/10.1016/j.jcis.2013.02.035

15 W. L. Zheng, W. L. Hu, S. Y. Chen, Y. Zheng, B. H. Zhou et al., Chinese J. Polym. Sci., 32, 169 (2014), https://doi.org/10.1007/s10118-014-1386-0

16 H. Hassan, A. Salama, A. K. El-Ziaty and M. ElSakhawy, Int. J. Biol. Macromol., 131, 520 (2019), https://doi.org/10.1016/j.ijbiomac.2019.03.087

17 J.-H. Lee, K.-H. Ko and B.-O. Park, J. Cryst. Growth, 247, $119 \quad$ (2003), https://doi.org/10.1016/S0022-0248(02)01907-3

18 Y. C. Kong, D. P. Yu, B. Zhang, W. Fang and S. Q.
Feng, Appl. Phys. Lett., 78, 407 (2001), https://doi.org/10.1063/1.1342050

19 H. Liu, Y. Zhang, H. Yang, W. Xiao and L. Sun, $J$. Chem., 2016, 1 (2016), https://doi.org/10.1155/2016/2862567

20 A. Fujishima and T. N. Rao, J. Chem. Sci., 109, 471 (1997), https://doi.org/10.1007/BF02869207

21 S. Baruah, M. Jaisai, R. Imani, M. M. Nazhad and J. Dutta, Sci. Technol. Adv. Mater., 11, 055002 (2010), https://doi.org/10.1088/1468-6996/11/5/055002

22 S. Baruah and J. Dutta, Sci. Technol. Adv. Mater., 10, 013001 (2009), https://doi.org/10.1088/1468$6996 / 10 / 1 / 013001$

23 A. El-Gendy, R. E. Abou-Zeid, A. Salama, M. A. Diab and M. El-Sakhawy, Egypt. J. Chem., 60, 1007 (2017),

https://doi.org/10.21608/ejchem.2017.1835.1153

24 A. Salama and M. El-Sakhawy, Int. J. Biol. Macromol., $\quad 92, \quad 920 \quad$ (2016), https://doi.org/10.1016/j.ijbiomac.2016.07.077

25 M. El-Sakhawy, S. Kamel, A. Salama and H.-A. S. Tohamy, Cellulose Chem. Technol., 52, 193 (2018), https://www.cellulosechemtechnol.ro/pdf/CCT34(2018)/p.193-200.pdf

${ }^{26}$ R. E. Abou-Zeid, A. Salama, Z. A. Al-Ahmed and N. S. Awwad, Cellulose Chem. Technol., 54, 237 (2020),

https://doi.org/10.35812/CelluloseChemTechnol.2020. 54.25

27 H.-A. S. Tohamy, S. Kamel, M. El-Sakhawy, M. A. Youssef, A. E. M. Abdallah et al., Egypt. J. Chem., 63, 3619

(2020), https://doi.org/10.21608/ejchem.2020.22915.2375

28 M. El-Sakhawy, H.-A. S. Tohamy, A. Salama and S. Kamel, Cellulose Chem. Technol., 53, 667 (2019), https://doi.org/10.35812/CelluloseChemTechnol.2019. 53.65

${ }^{29}$ F. Jones, H. Tran, D. Lindberg, L. Zhao and M. Hupa, Energ. Fuels, 27, 5663 (2013), https://doi.org/10.1021/ef400505u

30 A. K. Zak, R. Razali, W. H. Abd Majid and M. Darroudi, Int. J. Nanomed., 6, 1399 (2011), https://doi.org/10.2147/IJN.S19693

31 H.-L. Liu and T. C.-K. Yang, Process Biochem., 39, 475 (2003), https://doi.org/10.1016/S00329592(03)00084-0

32 S. A. A. Mohamed, M. El-Sakhawy and S. Kamel, Cellulose Chem. Technol., 52, 423 (2018), https://www.cellulosechemtechnol.ro/pdf/CCT56(2018)/p.423-431.pdf

33 A. Balcha, O. P. Yadav and T. Dey, Environ. Sci. Pollut. Res., 23, $25485 \quad$ (2016), https://doi.org/10.1007/s11356-016-7750-6

${ }_{34}$ M. H. Fallah, S. A. Fallah and M. A. Zanjanchi, Chinese J. Chem., 29, 1239 (2011), https://doi.org/10.1002/cjoc.201190230

${ }^{35}$ A. Ali, S. Ambreen, Q. Maqbool, S. Naz, M. F. Shams et al., J. Phys. Chem. Solids, 98, 174 (2016), https://doi.org/10.1016/j.jpcs.2016.07.007 